\title{
A highly stable metal-organic framework with well-matched pore cavity for efficient acetylene separation
}

\author{
Yang Chen ${ }^{1}$, Yadan $\mathrm{Du}^{1}$, Yong Wang ${ }^{1}$, Rajamani Krishna ${ }^{2}$, Libo $\mathrm{Li}^{1}$, Jiangfeng Yang ${ }^{1}$, \\ jinping $\mathrm{Li}^{1}$, and $\mathrm{Bin} \mathrm{Mu}^{3}$ \\ ${ }^{1}$ Taiyuan University of Technology \\ ${ }^{2}$ University of Amsterdam \\ ${ }^{3}$ Arizona State University
}

July 7, 2020

\begin{abstract}
Acetylene, an important petrochemical feedstock, is the starting chemical to produce many polymer products. Separating C2H2 from its by-product mixtures is still an energy-consuming process and remains challenging. Here, we present a metal-organic framework[Zn2(bpy)(btec)], with a desirable pore geometry and highly stable framework, which demonstrated a high separation performance of $\mathrm{C} 2 \mathrm{H} 2$ from simulated mixtures. With the desirable pore dimension and hydrogen bonding sites, Zn2(bpy)(btec) shows by far the both highest $\mathrm{C} 2 \mathrm{H} 2 / \mathrm{CO} 2$ and $\mathrm{C} 2 \mathrm{H} 2 / \mathrm{CO} 2$ uptake ratios, very high adsorption selectivities and moderately $\mathrm{C} 2 \mathrm{H} 2$ uptake of $93.5 \mathrm{~cm} 3{ }^{*} \mathrm{~cm}-3$ under $298 \mathrm{~K}$ and $1 \mathrm{~atm}$. Not only straightforwardly produced high purity of C2H4, but also recovered high purity of $\mathrm{C} 2 \mathrm{H} 2(>98 \%)$ in the regeneration process ( $>92 \%$ recovery). More notably, Zn2(bpy)(btec) can be straightforwardly synthesized at a large scale under environmentally friendly conditions, and its good water/chemical stability, thermostability, and cyclic stability highlight the promise of this molecular sieving material for industrial $\mathrm{C} 2 \mathrm{H} 2 \mathrm{separation}$.
\end{abstract}

\section{Introduction}

Both acetylene $\left(\mathrm{C}_{2} \mathrm{H}_{2}\right)$ and ethylene $\left(\mathrm{C}_{2} \mathrm{H}_{4}\right)$ are widely used as basic chemical materials in the petrochemical industry. The production of $\mathrm{C}_{2} \mathrm{H}_{4}$ is from the fractional distillation of petroleum, which usually coexists with $1 \% \mathrm{C}_{2} \mathrm{H}_{2} \cdot{ }^{1-3}$ In addition, carbon dioxide $\left(\mathrm{CO}_{2}\right)$ appears in the production of $\mathrm{C}_{2} \mathrm{H}_{2}$ by the thermal cracking process. ${ }^{4,5}$ Thus, selectively separation of $\mathrm{C}_{2} \mathrm{H}_{2}$ from $\mathrm{C}_{2} \mathrm{H}_{4} / \mathrm{C}_{2} \mathrm{H}_{2}$ or $\mathrm{CO}_{2} / \mathrm{C}_{2} \mathrm{H}_{2}$ mixtures is important to meet the requirement of polymer-grade $\mathrm{C}_{2} \mathrm{H}_{4}$ and high-purity $\mathrm{C}_{2} \mathrm{H}_{2}$ in petrochemical industrials. ${ }^{6,7}$ However, considering the small difference of molecular dimension of $\mathrm{C}_{2} \mathrm{H}_{2}(3.3 \AA \times 3.3 \AA \times 5.7 \AA), \mathrm{C}_{2} \mathrm{H}_{4}(3.3 \AA \times 4.2 \AA \times 4.8$ $\AA)$ and $\mathrm{CO}_{2}(3.2 \AA \times 3.3 \AA \times 5.4 \AA)$, as well as their similar physical properties, it is a very challenging to separate $\mathrm{C}_{2} \mathrm{H}_{2}$ from $\mathrm{C}_{2} \mathrm{H}_{4}$ or $\mathrm{CO}_{2}{ }^{8}{ }^{, 9}$ Although the cryogenic distillation for $\mathrm{C}_{2} \mathrm{H}_{2}$ separation is a very mature operation, it requires huge capital and energy input primarily due to the requirement of low temperature operation. ${ }^{10-12}$ It is necessary to develop a more efficient separation process such as porous materials based adsorptive separation with relatively low energy consumption and favorable regeneration. ${ }^{13,14}$

Porous materials, such as zeolites, metal-organic frameworks (MOFs) and covalent-organic frameworks (COFs), with porous structures, huge specific surface area, and designable frameworks have received extensive attention in recent years, ${ }^{15-17}$ as they present great potential to revolutionize some industrial applications, especially in separation, purification, and the storage of gases. ${ }^{18-20} \mathrm{An}$ ideal adsorbent for $\mathrm{C}_{2} \mathrm{H}_{2}$ separation is expected to be chemically stable, be able to capture trace $\mathrm{C}_{2} \mathrm{H}_{2}$ from $\mathrm{C}_{2} \mathrm{H}_{4}$ or other feed gas mixtures, and be able to regenerate easily. In recent years, a number of porous materials have been reported for $\mathrm{C}_{2} \mathrm{H}_{2} / \mathrm{C}_{2} \mathrm{H}_{4}$ separation through a synergistic approach of pore tuning and functionalization. ${ }^{21,22}$ In 2016, Xing's group ${ }^{14}$ reported the anion-pillared hybrid porous materials SIFSIX-2-Cu-i, with the specific binding 
sites and suitable pore space to effectively overcome the trade-off effect for $\mathrm{C}_{2} \mathrm{H}_{2}$ separation. In 2017, the first case of an ideal molecular sieve for $\mathrm{C}_{2} \mathrm{H}_{2} / \mathrm{C}_{2} \mathrm{H}_{4}$ was found called SIFSIX-14-Cu-i (UTSA-200) ${ }^{23}$, which with the ultrafine tuning of its pore size $(3.4 \AA)$, can not only effectively block $\mathrm{C}_{2} \mathrm{H}_{4}$ but also adsorb high amounts of $\mathrm{C}_{2} \mathrm{H}_{2}$, thus setting up the benchmarks for both $\mathrm{C}_{2} \mathrm{H}_{2}$ adsorption and $\mathrm{C}_{2} \mathrm{H}_{2} / \mathrm{C}_{2} \mathrm{H}_{4}$ separation. However, UTSA-200 can also take up a large amount of $\mathrm{CO}_{2}$ or $\mathrm{C}_{3} \mathrm{H}_{4}$ at the same conditions, ${ }^{24,25}$ which significantly restricts its separation performance for $\mathrm{C}_{2} \mathrm{H}_{2} / \mathrm{CO}_{2}$ and other multicomponent gases mixtures.

Traditional research on porous materials for gas separation mainly focused on those porous structures in the one-dimensional channel (Figure 1a) or cage type pore (Figure 1b). During our exploration of porous materials for $\mathrm{C}_{2} \mathrm{H}_{2}$ separation, we realized that one unique class of porous MOFs, which have interlayer pore cavities (Figure 1c) ${ }^{26,27}$ in their layered structures, had been overlooked. Compared to the traditional pore types, this kind of pore cavity has a narrow pore space, may exhibit multiple host-guest interactions with gas molecules, and thus could be utilized for selective separation of some specific gas component.

Herein, we report an ultramicroporous MOF $\left(\mathrm{Zn}_{2} \text { (bpy) (btec) }\right)^{28,29}$ that incorporates two-dimensional interlayer cavities, which enabled the full entrance of $\mathrm{C}_{2} \mathrm{H}_{2}$ and effectively blocked the $\mathrm{C}_{2} \mathrm{H}_{4}$ and $\mathrm{CO}_{2}$, thus exhibiting the benchmark $\mathrm{C}_{2} \mathrm{H}_{2} / \mathrm{C}_{2} \mathrm{H}_{4}$ and $\mathrm{C}_{2} \mathrm{H}_{2} / \mathrm{CO}_{2}$ uptake ratios. According to the breakthrough experiments, $\mathrm{C}_{2} \mathrm{H}_{2}$ can be directly removed from $\mathrm{C}_{2} \mathrm{H}_{2} / \mathrm{C}_{2} \mathrm{H}_{4}(1 / 99, \mathrm{v} / \mathrm{v})$ or $\mathrm{C}_{2} \mathrm{H}_{2} / \mathrm{CO}_{2}(50 / 50, \mathrm{v} / \mathrm{v})$ mixtures and high-purity $\mathrm{C}_{2} \mathrm{H}_{4}(>99.9999 \%), \mathrm{CO}_{2}(>99.999 \%)$, and $\mathrm{C}_{2} \mathrm{H}_{2}(>98 \%)$ can be obtained in the single separation process. More importantly, $\mathrm{Zn}_{2}$ (bpy)(btec) can be straightforwardly synthesized at the kilogram scale under room temperature in an aqueous solution. Its good chemical stability, water stability, thermal stability, and cyclic stability are well satisfied requirements of industrial application.

\section{Experimental}

Synthesis of $\left[\mathrm{Zn}_{2}\right.$ (bpy) (btec $\left.)\left(\mathrm{H}_{2} \mathrm{O}\right)_{2}\right] \cdot 2 \mathrm{H}_{2} \mathrm{O}$

\section{Hydrothermal synthesis}

The synthesis of the crystal sample was performed following a reported method with minor modifications. ${ }^{28}$ $0.1097 \mathrm{~g}(0.6 \mathrm{mmol})$ Zinc acetate, $0.1091 \mathrm{~g}(0.5 \mathrm{mmol})$ Pyromellitic dianhydride, $0.0781 \mathrm{~g}(0.5 \mathrm{mmol}) 4,4^{\prime}-$ Bipyridine and $10 \mathrm{~mL}$ deionized water were well mixed in a $25 \mathrm{~mL}$ Teflon-lined autoclave. Crystallization was carried out at $180{ }^{\circ} \mathrm{C}$ for 5 days. Then the autoclaves are cooled to room temperature. The crystals were filtered off, washed with hot water/ethanol mixture (1:1) for three times, then dried in air (yield: $0.1306 \mathrm{~g}$, $76.1 \%$ based on Zinc acetate).

\section{Rapid room temperature synthesis}

$0.1527 \mathrm{~g}$ (0.7 mmol) Pyromellitic dianhydride, $0.1093 \mathrm{~g}(0.7 \mathrm{mmol})$ 4,4'-Bipyridine and $5 \mathrm{~mL}$ deionized water were mixed in a $20 \mathrm{~mL}$ sealed vial with stirring at ambient temperature for $10 \mathrm{~min}$, then $200 \mu \mathrm{L} \mathrm{N \textrm {N } _ { 3 }} \cdot \mathrm{H}_{2} \mathrm{O}$ (25\%) was added into the vial. After the above mixture was thoroughly mixed, a $5 \mathrm{~mL}$ aqueous solution of $0.2569 \mathrm{~g}(1.4 \mathrm{mmol})$ Zinc acetate was added with stirring for $10 \mathrm{~min}$. Then the products were filtered off, washed with hot water/ethanol mixture (1:1) three times, then dried in air (yield: $0.3288 \mathrm{~g}, 82.1 \%$ based on 4,4'-Bipyridine).

\section{Large-scale synthesis}

Synthesis at the 1000-times scale was carried out as follows. White powder sample was obtained by mixing an aqueous solution $(0.65 \mathrm{~L})$ of Zinc acetate $\left(\mathrm{Zn}(\mathrm{Ac})_{2}, 1.64 \mathrm{~mol}, 0.3 \mathrm{~kg}\right)$ with an aqueous solution $(1.10 \mathrm{~L})$ of Pyromellitic dianhydride (0.7 mol, $0.1528 \mathrm{~kg}), 4,4^{\prime}$-Bipyridine $(0.7 \mathrm{~mol}, 0.1094 \mathrm{~kg})$ and $4 \mathrm{~mL} \mathrm{NH}_{3} \cdot \mathrm{H}_{2} \mathrm{O}$ $(25 \%)$. The crystallization was finished at ambient temperature after stirring for $30 \mathrm{~min}$, the sample was filtered, washed thoroughly with water/ethanol and dried under air, with a yield of $0.3236 \mathrm{~kg}(80.9 \%$ based on 4,4'-Bipyridine).

Characterization

The crystallinity and phase purity of the materials were measured by powder X-ray diffraction (PXRD) on 
a Bruker D8 ADVANCE X-ray diffractometer with $\mathrm{Cu}-\mathrm{K} \alpha(\lambda=1.5418 \AA)$ radiation operated at $40 \mathrm{kV}$ and $40 \mathrm{~mA}$. Scanning was performed over the $2 \vartheta$ range of $5-50^{\circ}$ at $4 \% \mathrm{~min}$. Scanning electron microscopy (SEM) images were obtained using a Hitachi SEM (SU8010, Hitachi, Japan) equipped with a Horiba X-Max 50 EDX system. The TGA of the samples was collected on a thermal analyzer (NETZSCH, STA 449 F5) at a heating rate of $5{ }^{\circ} \mathrm{C} / \mathrm{min}$ under air atmosphere. $\mathrm{CO}_{2}$ adsorption/desorption isotherms were obtained using an ASAP 2460 Surface Area and Porosity Analyzer at $273 \mathrm{~K}$.

\section{Adsorption experiment}

The purities of the acetylene, ethylene and carbon dioxide were higher than $99.99 \%$. Their adsorption isotherms were collected with an Intelligent Gravimetric Analyser (IGA 001, Hiden, UK). Samples were activated under vacuum at $150{ }^{\circ} \mathrm{C}$ overnight or until no further weight loss was observed. Adsorption equilibrium data was collected once a stable pressure (more than 20 adsorption points were recorded from 0 to 1 bar) and weight was maintained for at least $40 \mathrm{~min}$ to reach an adsorption equilibrium at each point along the isotherm.

\section{Breakthrough tests}

The breakthrough experiments for $\mathrm{C}_{2} \mathrm{H}_{2} / \mathrm{C}_{2} \mathrm{H}_{4}(1 / 99, \mathrm{v} / \mathrm{v})$ mixtures were carried out at a flow rate of 1.25 $\mathrm{mL} / \mathrm{min}(298 \mathrm{~K}, 1.01 \mathrm{bar})$. In the separation experiment, $\mathrm{Zn}_{2}$ (bpy)(btec) sample (3.0575 g) was packed into $\Phi 4 \times 275 \mathrm{~mm}$ stainless steel column, and the column was activated under reduced pressure at $150{ }^{\circ} \mathrm{C}$ overnight. The experimental set-up consisted of two fixed-bed stainless steel reactors. One reactor was loaded with the adsorbent, while the other reactor was used as a blank control group to stabilize the gas flow. The horizontal reactors were placed in a temperature-controlled environment, maintained at $298 \mathrm{~K}$. The flow rates of all gas mixtures were regulated by mass flow controllers, and the effluent gas stream from the column was monitored by gas chromatography. Prior to the breakthrough experiment, we activated the sample by flushing the adsorption bed with helium gas for 2 hours at $150{ }^{\circ} \mathrm{C}$. Subsequently, the column was allowed to equilibrate at the measurement rate before we switched the gas flow.

\section{Results and Discussion}

Structure characterization

The synthesized $\left[\mathrm{Zn}_{2}\right.$ (bpy) (btec) $\left.\left(\mathrm{H}_{2} \mathrm{O}\right)_{2}\right] \cdot 2 \mathrm{H}_{2} \mathrm{O}$ has a two-dimensional structure, each layer is formed by Zn coordinated with bpy and btec, and $\mathrm{H}_{2} \mathrm{O}$ molecules between layers provide multiple hydrogen bonding sites to connect the two layers ${ }^{28}$. In this work, we investigated the rapid synthesis and large-scale synthesis processes of these materials, the PXRD patterns of these samples were matched well with the simulated one, and the SEM images show that the samples have relatively high crystallinity (Figure S1 and S2). After guest removal, $\mathrm{Zn}_{2}$ (bpy) (btec) still shows porosity with the pore cavities of $3.6 \AA \times 3.8 \AA \times 6.6 \AA$ (Figure $2 \mathrm{a}$, b). These cavities match well with the size and shape of $\mathrm{C}_{2} \mathrm{H}_{2}(3.3 \AA \times 3.3 \AA \times 5.7 \AA)$, suggesting a potential application for $\mathrm{C}_{2} \mathrm{H}_{2}$ separation.

The porosity in $\mathrm{Zn}_{2}$ (bpy)(btec) was established by $\mathrm{CO}_{2}$ sorption at $273 \mathrm{~K}$. As shown in Figure $\mathrm{S} 3$, the $\mathrm{CO}_{2}$ adsorption isotherms slowly increase with increasing pressure. By using the Dubinin-Radushkevich equation, the surface area of $\mathrm{Zn}_{2}$ (bpy)(btec) was calculated to be $397 \mathrm{~m}^{2} / \mathrm{g}$, and its pore-size is around $3.6 \AA$ (Figure S3). The pore cavity between two layers is about $3.6 \AA \times 3.8 \AA \times 6.6 \AA$, which is slightly larger than the size of $\mathrm{C}_{2} \mathrm{H}_{2}, \mathrm{CO}_{2}$ and smaller than $\mathrm{C}_{2} \mathrm{H}_{4}$, thus could be used for $\mathrm{C}_{2} \mathrm{H}_{2} / \mathrm{C}_{2} \mathrm{H}_{4}$ and $\mathrm{C}_{2} \mathrm{H}_{2} / \mathrm{CO}_{2}$ separation.

Single-gas sorption isotherm

Pure component equilibrium adsorption isotherms for $\mathrm{C}_{2} \mathrm{H}_{2}, \mathrm{C}_{2} \mathrm{H}_{4}$ and $\mathrm{CO}_{2}$ were measured at $298 \mathrm{~K}$ up to 1 bar, as presented in Figure 3a. The $\mathrm{C}_{2} \mathrm{H}_{2}$ uptake on $\mathrm{Zn}_{2}$ (bpy)(btec) reached $93.5 \mathrm{~cm}^{3} \mathrm{~cm}^{-3}$ at $298 \mathrm{~K}$ and 1 bar, significantly higher than that of $\mathrm{C}_{2} \mathrm{H}_{4}$ and $\mathrm{CO}_{2}$ at the same conditions. Notably, through size sieving by the appropriate aperture, $\mathrm{Zn}_{2}$ (bpy)(btec) presents the $\mathrm{C}_{2} \mathrm{H}_{2}$ uptake of $93.5 \mathrm{~cm}^{3} \mathrm{~cm}^{-3}$, very low $\mathrm{C}_{2} \mathrm{H}_{4}$ uptake of $9.1 \mathrm{~cm}^{3} \mathrm{~cm}^{-3}$ and low $\mathrm{CO}_{2}$ uptake of $28.9 \mathrm{~cm}^{3} \mathrm{~cm}^{-3}$ (298 $\mathrm{K}$ and 1 bar), giving an excellent uptake 
ratio of $\mathrm{C}_{2} \mathrm{H}_{2}$ over $\mathrm{C}_{2} \mathrm{H}_{4}$ (10.31) and $\mathrm{CO}_{2}(3.23)$, which are the highest values among the indicated MOFs (Supporting information, Table S2 and S3).

To compare the separation properties of $\mathrm{Zn}_{2}$ (bpy)(btec) with other top-performing MOFs, its ideal adsorbed solution theory (IAST) selectivity of $\mathrm{C}_{2} \mathrm{H}_{2}$ over $\mathrm{C}_{2} \mathrm{H}_{4}$ and $\mathrm{CO}_{2}$ were calculated on their single-component isotherms (Figure 3a). The gas mixtures were selected as $\mathrm{C}_{2} \mathrm{H}_{2} / \mathrm{C}_{2} \mathrm{H}_{4}(1: 99, \mathrm{v} / \mathrm{v})$ and $\mathrm{C}_{2} \mathrm{H}_{2} / \mathrm{CO}_{2}(50: 50$, $\mathrm{v} / \mathrm{v}$ ) at a total gas pressure of 1 bar and $298 \mathrm{~K}$, to mimic the composition of the industrial purification process. As seen in Figure $3 \mathrm{~b}, \mathrm{c}, \mathrm{Zn}_{2}$ (bpy)(btec) exhibits an extraordinarily high selectivity of over 107.8 for the $\mathrm{C}_{2} \mathrm{H}_{2} / \mathrm{C}_{2} \mathrm{H}_{4}$ mixture and 33.3 for the $\mathrm{C}_{2} \mathrm{H}_{2} / \mathrm{CO}_{2}$ mixture, notably higher than the previous benchmark SIFSIX-2-Cu-i $(44.54)^{14}$, M'MOF-3a $(24.03)^{30}$, CPL-1 $(26.8)^{31}$ and ELM-12 (14.8 $)^{32}$ for $\mathrm{C}_{2} \mathrm{H}_{2} / \mathrm{C}_{2} \mathrm{H}_{4}$ separation, and FeNi-M'MOF (24) ${ }^{33}$ HOF-3a (21) $)^{34}$, UTSA-74 (9) ${ }^{35}$, TIFSIX-2-Cu-i (6.5) ${ }^{36}$ and for $\mathrm{C}_{2} \mathrm{H}_{2} / \mathrm{CO}_{2}$ separation.

In industrial applications, energy cost in the regeneration process is also an unavoidable problem and should be taken into consideration. The interactions between the adsorbents and $\mathrm{C}_{2} \mathrm{H}_{2}$ are evaluated by calculating the isosteric heats of adsorption $\left(\mathrm{Q}_{\mathrm{st}}\right)$, which is measured from the single component isotherms at different temperatures (Figure 3d). The calculated $\mathrm{Q}_{\mathrm{st}}$ of $\mathrm{Zn}_{2}$ (bpy)(btec) at zero coverage for $\mathrm{C}_{2} \mathrm{H}_{2}$ is $28.7 \mathrm{~kJ} / \mathrm{mol}$ (Figure S4), which is much lower than those values reported in other MOFs with open metal sites such as MOF-74 series (47 kJ/mol for Fe-MOF-74). ${ }^{12}$ Thus, the molecular sieving based adsorption not only avoided excessive temperature fluctuations during the adsorption process but also decreased the cost and energy requirement in the regeneration process, which indicates advantages of $\mathrm{Zn}_{2}(\mathrm{bpy})(\mathrm{btec})$ in real industrial applications. In addition, comparing with other top-performing materials (Table $\mathrm{S} 2, \mathrm{~S} 3$ ), $\mathrm{Zn}_{2}(\mathrm{bpy})(\mathrm{btec})$ exhibits the lowest total $\mathrm{C}_{2} \mathrm{H}_{4}$ and $\mathrm{CO}_{2}$ loading in normal conditions (Figure 3e), and less co-adsorption will lead to a higher $\mathrm{C}_{2} \mathrm{H}_{2}$ purity in the generation process. Besides, this material exhibits the highest $\mathrm{C}_{2} \mathrm{H}_{2} / \mathrm{C}_{2} \mathrm{H}_{4}$ uptake ratio (10.31) and $\mathrm{C}_{2} \mathrm{H}_{2} / \mathrm{CO}_{2}$ uptake ratio (3.23), as well as extraordinarily high selectivity $(107.8,33.3)$ (Figure 3f), which makes it one of the most promising materials for the efficient $\mathrm{C}_{2} \mathrm{H}_{2}$ separation from $\mathrm{C}_{2} \mathrm{H}_{4}$ or $\mathrm{CO}_{2}$ mixtures.

Breakthrough separation

Furthermore, we performed actual breakthrough experiments on $\mathrm{Zn}_{2}$ (bpy)(btec) to establish the feasibility of $\mathrm{C}_{2} \mathrm{H}_{2} / \mathrm{C}_{2} \mathrm{H}_{4}$ and $\mathrm{C}_{2} \mathrm{H}_{2} / \mathrm{CO}_{2}$ separations, in which $\mathrm{C}_{2} \mathrm{H}_{2} / \mathrm{C}_{2} \mathrm{H}_{4}(\mathrm{v} / \mathrm{v}, 1 / 99)$ and $\mathrm{C}_{2} \mathrm{H}_{2} / \mathrm{CO}_{2}(\mathrm{v} / \mathrm{v}, 50 / 50)$ mixtures were used as feeds to mimic the industrial process conditions (Figure 4 and $\mathrm{S} 6$ ). As shown in Figure 4a, c, only after several minutes, $\mathrm{C}_{2} \mathrm{H}_{4}$ or $\mathrm{CO}_{2}$ first eluted through the bed to yield a polymer-grade gas and the purity of $\mathrm{C}_{2} \mathrm{H}_{4}$ monitored at the outlet was $>99.9999 \%$. Then, after a long period of time (130 min for $\mathrm{C}_{2} \mathrm{H}_{2} / \mathrm{C}_{2} \mathrm{H}_{4}, 50 \mathrm{~min}$ for $\left.\mathrm{C}_{2} \mathrm{H}_{2} / \mathrm{CO}_{2}\right), \mathrm{C}_{2} \mathrm{H}_{2}$ broke through from the adsorption bed. During this process, $\mathrm{C}_{2} \mathrm{H}_{2}$ was clearly captured by $\mathrm{Zn}_{2}$ (bpy) (btec), with the concentration of the impurities decreased to lower than $1 \mathrm{ppm}$ for $\mathrm{C}_{2} \mathrm{H}_{4}$ and $10 \mathrm{ppm}$ for $\mathrm{CO}_{2}$. Polymer-grade $\mathrm{C}_{2} \mathrm{H}_{4}$ and high purity of $\mathrm{CO}_{2}$ were directly collected at the outlet. From the desorption curves in Figure $4 \mathrm{~b}$, d, it can be found that adsorbates were fully desorbed from the materials in 20 minutes. Due to the high $\mathrm{C}_{2} \mathrm{H}_{2} / \mathrm{C}_{2} \mathrm{H}_{4}$ and $\mathrm{C}_{2} \mathrm{H}_{2} / \mathrm{CO}_{2}$ uptake ratios and selectivities, a high purity of $\mathrm{C}_{2} \mathrm{H}_{2}$ over $98.5 \%$ (b) or $92.5 \%$ (d) were generated, respectively.

The kinetic ad/desorption rate of $\mathrm{C}_{2} \mathrm{H}_{2}$ was also investigated in Figure $\mathrm{S} 8$ and S9, showing that $\mathrm{Zn}_{2}$ (bpy)(btec) has a high kinetic ad/desorption rate, and therefore that $\mathrm{C}_{2} \mathrm{H}_{2}$ can be saturated or fully desorbed in about ten minutes. In addition, the desorption and recycling measurements revealed that this material can maintain its $\mathrm{C}_{2} \mathrm{H}_{2}$ capture ability and high selectivity in several repeated adsorption and separation cycles (Figure 4b, d, and S7). The breakthrough time remains almost unchanged during five cyclic breakthrough experiments, confirming the good recyclability of this material for the $\mathrm{C}_{2} \mathrm{H}_{2} / \mathrm{C}_{2} \mathrm{H}_{4}$ and $\mathrm{C}_{2} \mathrm{H}_{2} / \mathrm{CO}_{2}$ separation.

Generally, in the real production process, the feed gas also contains some other components, which is a tremendous challenge in the recovery of $\mathrm{C}_{2} \mathrm{H}_{2}$ from such refinery gas. Therefore, we investigated the singlecomponent adsorption isotherms of some main components of refinery gas $\left(\mathrm{CH}_{4}, \mathrm{C}_{2} \mathrm{H}_{2}, \mathrm{C}_{2} \mathrm{H}_{4}, \mathrm{C}_{2} \mathrm{H}_{6}, \mathrm{C}_{3} \mathrm{H}_{4}\right.$, $\mathrm{C}_{3} \mathrm{H}_{6}$ and $\left.\mathrm{C}_{3} \mathrm{H}_{8}\right)$ and common gas components $\left(\mathrm{CO}_{2}, \mathrm{H}_{2}, \mathrm{~N}_{2}\right.$ and $\left.\mathrm{O}_{2}\right)$ as seen in Figure $5 \mathrm{a}$, b. Based 
on the well-matched pore cavity of $\mathrm{Zn}_{2}$ (bpy)(btec), this material selectively adsorbs $\mathrm{C}_{2} \mathrm{H}_{2}$ and blocks most other molecules to achieve an admirable sieving effect (Fig. 4a). The uptakes of most of the gases were below $10 \mathrm{~cm}^{3} \mathrm{~cm}^{-3}$ at 1 bar and $298 \mathrm{~K}$. Furthermore, the gas mixtures separation process was carried out on this molecular sieve material for the recovery of $\mathrm{C}_{2} \mathrm{H}_{2}$ from the simulated steam cracking mixtures. As can be seen from the breakthrough curves, most of the mixture gases eluted through the fixed bed quickly and a trace amount of $\mathrm{C}_{2} \mathrm{H}_{2}$ was totally adsorbed during the long retention time. In the generation process, the adsorbent was fully desorbed in 20 minutes and obtained high purity $\mathrm{C}_{2} \mathrm{H}_{2}(>98 \%)$. The multicomponent separation and desorption tests show strong evidence of the efficient $\mathrm{C}_{2} \mathrm{H}_{2}$ separation ability of $\mathrm{Zn}_{2}$ (bpy)(btec) materials, which has initiated the promise of MOF materials for this very important industrial application.

Grand canonical Monte Carlo simulations

To have a better insight into the excellent $\mathrm{C}_{2} \mathrm{H}_{2}$ separation ability of $\mathrm{Zn}_{2}$ (bpy)(btec), GCMC simulations were performed to structurally elucidate how $\mathrm{C}_{2} \mathrm{H}_{2}$ molecules are adsorbed in this MOF. ${ }^{35,37,38}$ The calculated binding sites of $\mathrm{C}_{2} \mathrm{H}_{2}$ are shown in Figure 6 . The $\mathrm{C}_{2} \mathrm{H}_{2}$ molecules are preferentially located in the pore cavities between the layers of $\mathrm{Zn}_{2}$ (bpy)(btec). The $\mathrm{C}-\mathrm{H}^{* * *} \mathrm{O}$ hydrogen bonds of each $\mathrm{C}_{2} \mathrm{H}_{2}$ molecule interacts with two oxygen molecule with a distance of $2.2^{\sim} 2.33 \mathrm{~A}$, which are much shorter than the sum of the van der Waals radii of oxygen $(1.52 \mathrm{~A})$ and hydrogen $(1.20 \mathrm{~A})$ atoms, indicating a relatively strong interaction.

Scalable synthesis and stability

In order to promote the industrialization of MOFs materials, it is the general trend to produce stable MOF materials at low costs and with simple operation processes. Therefore, a water-based and scalable synthesis was developed at room temperature for the large-scale preparation of $\left[\mathrm{Zn}_{2}(\mathrm{bpy})(\mathrm{btec})\left(\mathrm{H}_{2} \mathrm{O}\right)_{2}\right]{ }^{*} 2 \mathrm{H}_{2} \mathrm{O} .{ }^{39} \mathrm{As}$ shown in Figure 7a, only by mixing the metal salt and the ligands in aqueous solution and stirring for 30 minutes, then filtering and drying, can we obtain more than $320 \mathrm{~g}$ of product at room temperature. TGA and DSC were tested on $\left[\mathrm{Zn}_{2} \text { (bpy) (btec) }\left(\mathrm{H}_{2} \mathrm{O}\right)_{2}\right]^{*} 2 \mathrm{H}_{2} \mathrm{O}$ to explore its thermal stabilities (Figure $7 \mathrm{~b}$ ). Below $150 \operatorname{deg}$, the initial weight loss of $\sim 14 \%$ was accounted for by the loss of water molecules, and then $\mathrm{Zn}_{2}$ (bpy)(btec) can stabilize up to about $410 \operatorname{deg} \mathrm{C}$ before its decomposition.

Besides, the adsorbents require relatively high thermostability to keep a long operation lifetime, The real $\mathrm{C}_{2} \mathrm{H}_{2}$-relevant separation tasks are typically implemented under more extreme conditions, typically containing a trace amount of water and acidic gases. ${ }^{40}$ Herein, the structural stability of $\mathrm{Zn}_{2}$ (bpy)(btec) was examined in detail. As depicted in Figure 7c, d, the PXRD patterns of those materials treated under extreme conditions (acid, base, or boiling water) coincide with those of pristine samples, which indicates that its structure has no framework collapse and still retains its crystallinity. After such treatment, its $\mathrm{C}_{2} \mathrm{H}_{2}$ adsorption is largely maintained, comparable to the initial value (Figure S11), which demonstrated that this material is highly stable in the acidic/basic solutions $\left(\mathrm{pH}=1^{\sim} 13\right)$, even in the water up to $120 \operatorname{degC}$. The water and thermal stability of $\mathrm{Zn}_{2}$ (bpy)(btec) has been superior to most $\mathrm{C}_{2} \mathrm{H}_{2}$-separated MOFs (Figure 7e). Its exceptionally high stability is due to its dense structure forming by the strong multiple hydrogen bonding interactions and offset $\pi-\pi$ stacking interactions (Figure S12).

\section{Conclusion}

In summary, we have identified an abnormally layered MOF $\left(\mathrm{Zn}_{2}\right.$ (bpy)(btec)) for the highly efficient separation of $\mathrm{C}_{2} \mathrm{H}_{2}$ from $\mathrm{C}_{2} \mathrm{H}_{4}$ and $\mathrm{CO}_{2}$ mixtures. The interlayer pores cavity can exactly adsorb $\mathrm{C}_{2} \mathrm{H}_{2}$ and block $\mathrm{C}_{2} \mathrm{H}_{4}$ or the other C1-C3 hydrocarbons, resulting in by far both the highest $\mathrm{C}_{2} \mathrm{H}_{2} / \mathrm{C}_{2} \mathrm{H}_{4}$ and $\mathrm{C}_{2} \mathrm{H}_{2} / \mathrm{CO}_{2}$ uptake ratios $(10.31,3.23)$ and superior IAST selectivities $(107.8,33.3)$ among the rigid MOFs. Through size sieving by the appropriate aperture, this MOF achieves efficient separation of $\mathrm{C}_{2} \mathrm{H}_{2} / \mathrm{C}_{2} \mathrm{H}_{4}(1 / 99, \mathrm{v} / \mathrm{v})$, $\mathrm{C}_{2} \mathrm{H}_{2} / \mathrm{CO}_{2}(50 / 50, \mathrm{v} / \mathrm{v})$ and simulated steam cracking mixtures, finally obtaining a polymer grade of $\mathrm{C}_{2} \mathrm{H}_{4}$ (99.9999\%) and a high purity of $\mathrm{C}_{2} \mathrm{H}_{2}(98 \%)$. Furthermore, the synthesis of this material is easily scale-up at an environmentally friendly condition and its structure can be maintained in solutions with a wide range of $\mathrm{pH}\left(1^{\sim} 13\right)$ as well as in the boiling $(373 \mathrm{~K})$ water. These desirable properties of $\mathrm{Zn}_{2}$ (bpy)(btec) demonstrated that this new MOF material is a promising adsorbent, which has great potential to be used for the practical 
$\mathrm{C}_{2} \mathrm{H}_{2}$ production process.

Acknowledgements

We gratefully acknowledge the financial support from the National Natural Science Foundation of China (No. 21908155, 21922810 and 21878205), Natural Science Foundation for Young Scientists of Shanxi Province (No. 201901D211053).

Conflict of interest

The authors declare no conflict of interest.

\section{References}

1. Chen K-J, Madden DG, Mukherjee S, et al. Synergistic sorbent separation for one-step ethylene purification from a four-component mixture. Science . 2019;366(6462):241-246.

2. Hu TL, Wang H, Li B, et al. Microporous metal-organic framework with dual functionalities for highly efficient removal of acetylene from ethylene/acetylene mixtures. Nat Commun . 2015;6:7328.

3. Wang J, Xie D, Zhang Z, et al. Efficient adsorption separation of acetylene and ethylene via supported ionic liquid on metal-organic framework. AIChE J . 2016;63(6):2165-2175.

4. Matsuda R, Kitaura R, Kitagawa S, et al. Highly controlled acetylene accommodation in a metalorganic microporous material. Nature . 2005;436(7048):238-241.

5. Pei J, Shao K, Wang JX, et al. A Chemically Stable Hofmann-Type Metal-Organic Framework with Sandwich-Like Binding Sites for Benchmark Acetylene Capture. Adv Mater . 2020:e1908275.

6. Li J, Jiang L, Chen S, et al. Metal-Organic Framework Containing Planar Metal-Binding Sites: Efficiently and Cost-Effectively Enhancing the Kinetic Separation of $\mathrm{C}_{2} \mathrm{H}_{2} / \mathrm{C}_{2} \mathrm{H}_{4} . J$ Am Chem Soc . 2019;141(9):3807-3811.

7. Belmabkhout Y, Zhang Z, Adil K, et al. Hydrocarbon recovery using ultra-microporous fluorinated MOF platform with and without uncoordinated metal sites: I- structure properties relationships for $\mathrm{C}_{2} \mathrm{H}_{2} / \mathrm{C}_{2} \mathrm{H}_{4}$ and $\mathrm{CO}_{2} / \mathrm{C}_{2} \mathrm{H}_{2}$ separation. Chem Eng J . 2019;359:32-36.

8. Li JR, Kuppler RJ, Zhou HC. Selective gas adsorption and separation in metal-organic frameworks. Chem Soc Rev . 2009;38(5):1477-1504.

9. Foo ML, Matsuda R, Hijikata Y, et al. An Adsorbate Discriminatory Gate Effect in a Flexible Porous Coordination Polymer for Selective Adsorption of $\mathrm{CO}_{2}$ over $\mathrm{C}_{2} \mathrm{H}_{2}$. J Am Chem Soc . 2016;138(9):30223030 .

10. Sholl DS, Lively RP. Seven chemical separations to change the world.Nature . 2016;532(7600):435-437.

11. Zhao X, Yang Q, Xu D, et al. Design and screening of ionic liquids for $\mathrm{C}_{2} \mathrm{H}_{2} / \mathrm{C}_{2} \mathrm{H}_{4}$ separation by COSMO-RS and experiments. AIChE J . 2015;61(6):2016-2027.

12. Bloch ED, Queen WL, Krishna R, Zadrozny JM, Brown CM, Long JR. Hydrocarbon separations in a metal-organic framework with open iron(II) coordination sites. Science . 2012;335(6076):1606-1610.

13. He Y, Xiang S, Chen B. A microporous hydrogen-bonded organic framework for highly selective $\mathrm{C}_{2} \mathrm{H}_{2} / \mathrm{C}_{2} \mathrm{H}_{4}$ separation at ambient temperature. J Am Chem Soc . 2011;133(37):14570-14573.

14. Cui X, Chen K, Xing H, et al. Pore chemistry and size control in hybrid porous materials for acetylene capture from ethylene.Science. 2016;353(6295):141-144.

15. Férey G, Serre C, Devic T, et al. Why hybrid porous solids capture greenhouse gases? Chem Soc Rev . 2011;40(2):550-562.

16. Chen Z, Li P, Anderson R, et al. Balancing volumetric and gravimetric uptake in highly porous materials for clean energy. Science . 2020;368(6488):297.

17. Rieth AJ, Wright AM, Dincă M. Kinetic stability of metal-organic frameworks for corrosive and coordinating gas capture. Nat Rev Mater . 2019;4:708-725.

18. Liao P-Q, Huang N-Y, Zhang W-X, Zhang J-P, Chen X-M. Controlling guest conformation for efficient purification of butadiene. Science. 2017;356(6343):1193.

19. Shan $\mathrm{B}, \mathrm{Yu}$ J, Armstrong MR, et al. A cobalt metal-organic framework with small pore size for adsorptive separation of $\mathrm{CO}_{2}$ over $\mathrm{N}_{2}$ and $\mathrm{CH}_{4}$. AIChE $J$. 2017;63(10):4532-4540. 
20. Yang S, Ramirez-Cuesta AJ, Newby R, et al. Supramolecular binding and separation of hydrocarbons within a functionalized porous metal-organic framework. Nat Chem . 2014;7(2):121-129.

21. Furukawa H, Ko N, Go YB, et al. Ultrahigh Porosity in Metal-Organic Frameworks. Science . 2010;329(5990):424.

22. Lv D, Chen J, Chen Y, et al. Moisture stability of ethane-selective $\mathrm{Ni}(\mathrm{II}), \mathrm{Fe}(\mathrm{III}), \mathrm{Zr}(\mathrm{IV})$-based metal-organic frameworks. AIChE J . 2019;65(8):e16616.

23. Li B, Cui X, O'Nolan D, et al. An Ideal Molecular Sieve for Acetylene Removal from Ethylene with Record Selectivity and Productivity.Adv Mater . 2017;29:1704210.

24. Jiang M, Li B, Cui X, et al. Controlling Pore Shape and Size of Interpenetrated Anion-Pillared Ultramicroporous Materials Enables Molecular Sieving of $\mathrm{CO}_{2}$ Combined with Ultrahigh Uptake Capacity. ACS Appl Mater Interfaces . 2018;10(19):16628-16635.

25. Li L, Wen H-M, He C, et al. A Metal-Organic Framework with Suitable Pore Size and Specific Functional Sites for the Removal of Trace Propyne from Propylene. Angew Chem, Int Ed . 2018;57(46):15183-15188.

26. Lin RB, Li L, Wu H, et al. Optimized Separation of Acetylene from Carbon Dioxide and Ethylene in a Microporous Material. J Am Chem Soc . 2017;139(23):8022-8028.

27. Li L, Lin R-B, Krishna R, et al. Flexible-Robust Metal-Organic Framework for Efficient Removal of Propyne from Propylene. J Am Chem Soc . 2017;139(23):7733-7736.

28. Wu C-D, Lu C-Z, Wu D-M, Zhuang H-H, Huang J-S. Hydrothermal synthesis of two new zinc coordination polymers with mixed ligands. Inorg Chem Commun . 2001;4(10):561-564.

29. Yang S-Y, Sun Z-G, Long L-S, Huang R-B, Zheng L-S. Crystal structure of a 2D coordination polymer: Dizinc pyromellitate 4, 4'-bipyridine tetrahydrate. Main Group Met Chem . 2002;25(11):699-700.

30. Xiang SC, Zhang Z, Zhao CG, et al. Rationally tuned micropores within enantiopure metal-organic frameworks for highly selective separation of acetylene and ethylene. Nat Commun . 2011;2:204.

31. Zheng F, Guo L, Gao B, et al. Engineering the Pore Size of Pillared-Layer Coordination Polymers Enables Highly Efficient Adsorption Separation of Acetylene from Ethylene. ACS Appl Mater Interfaces . 2019;11(31):28197-28204.

32. Li L, Lin R-B, Krishna R, et al. Efficient separation of ethylene from acetylene/ethylene mixtures by a flexible-robust metal-organic framework. J Mater Chem A . 2017;5:18984-18988.

33. Gao J, Qian X, Lin RB, et al. Mixed Metal-Organic Framework with Multiple Binding Sites for Efficient $\mathrm{C}_{2} \mathrm{H}_{2} / \mathrm{CO}_{2}$ Separation. Angew Chem Int Ed . 2020;59(11):4396-4400.

34. Li P, He Y, Zhao Y, et al. A rod-packing microporous hydrogen-bonded organic framework for highly selective separation of $\mathrm{C}_{2} \mathrm{H}_{2} / \mathrm{CO}_{2}$ at room temperature. Angew Chem Int Ed . 2015;54(2):574-577.

35. Luo F, Yan C, Dang L, et al. UTSA-74: A MOF-74 Isomer with Two Accessible Binding Sites per Metal Center for Highly Selective Gas Separation. J Am Chem Soc . 2016;138(17):5678-5684.

36. Chen K-J, Scott Hayley S, Madden David G, et al. Benchmark $\mathrm{C}_{2} \mathrm{H}_{2} / \mathrm{CO}_{2}$ and $\mathrm{CO}_{2} / \mathrm{C}_{2} \mathrm{H}_{2}$ Separation by Two Closely Related Hybrid Ultramicroporous Materials. Chem . 2016;1(5):753-765.

37. Hao HG, Zhao YF, Chen DM, et al. Simultaneous Trapping of $\mathrm{C}_{2} \mathrm{H}_{2}$ and $\mathrm{C}_{2} \mathrm{H}_{6}$ from a Ternary Mixture of $\mathrm{C}_{2} \mathrm{H}_{2} / \mathrm{C}_{2} \mathrm{H}_{4} / \mathrm{C}_{2} \mathrm{H}_{6}$ in a Robust Metal-Organic Framework for the Purification of $\mathrm{C}_{2} \mathrm{H}_{4}$. Angew Chem Int Ed . 2018;57(49):16067-16071.

38. Zhang C, Wang L, Maurin G, Yang Q. In Silico Screening of MOFs with open copper sites for $\mathrm{C}_{2} \mathrm{H}_{2} / \mathrm{CO}_{2}$ separation.AIChE $J$. 2018;64(11):4089-4096.

39. Lin RB, Li L, Zhou HL, et al. Molecular sieving of ethylene from ethane using a rigid metal-organic framework. Nat Mater . 2018;18(12):1128-1133.

40. Weissermel K. Arpe H-J. Industrial Organic Chemistry, 4 ${ }^{\text {th }}$ ed., Wiley-VCH, Weinheim, Germany 2003.

Figure captions:

Figure 1. Schematic illustration of the representative porous structures in MOFs: (a) One-dimensional channel, (b) Cage type pore, and (c) Interlayer cavity.

Figure 2. (a, b) The crystal structures and channel shapes of $\mathrm{Zn}_{2}$ (bpy)(btec). (c) Comparison of molecular size difference of $\mathrm{C}_{2} \mathrm{H}_{2}$ and $\mathrm{C}_{2} \mathrm{H}_{4}$ (Color code: Zn, green; $\mathrm{O}$, red; $\mathrm{N}$, light blue; $\mathrm{C}$, gray). 
Figure 3. (a) Single-component sorption isotherms of $\mathrm{C}_{2} \mathrm{H}_{2}, \mathrm{C}_{2} \mathrm{H}_{4}$, and $\mathrm{CO}_{2}$ at $298 \mathrm{~K}$ for $\mathrm{Zn}_{2}$ (bpy)(btec). (b, c) IAST selectivities of $\mathrm{C}_{2} \mathrm{H}_{2} / \mathrm{C}_{2} \mathrm{H}_{4}(1 / 99)$ and $\mathrm{C}_{2} \mathrm{H}_{2} / \mathrm{CO}_{2}$ (50/50) mixtures on some benchmark materials. (d) Adsorption isotherms of $\mathrm{C}_{2} \mathrm{H}_{2}$ for $\mathrm{Zn}_{2}$ (bpy)(btec) at 288-308 K. (e) $\mathrm{C}_{2} \mathrm{H}_{4}$ and $\mathrm{CO}_{2}$ uptakes of different MOF materials at 1 bar and $298 \mathrm{~K}$. (f) Comparison of $\mathrm{C}_{2} \mathrm{H}_{2} / \mathrm{C}_{2} \mathrm{H}_{4}(1 / 99)$ and $\mathrm{C}_{2} \mathrm{H}_{2} / \mathrm{CO}_{2}(50 / 50)$ IAST selectivities and $\mathrm{C}_{2} \mathrm{H}_{2}-\mathrm{C}_{2} \mathrm{H}_{4}-\mathrm{CO}_{2}$ uptake ratios of different adsorbents at 1 bar and $298 \mathrm{~K}$.

Figure 4. Experimental breakthrough $(298 \mathrm{~K}, 1$ bar) and desorption (333 K, 1 bar) curves for $\mathrm{C}_{2} \mathrm{H}_{2} / \mathrm{C}_{2} \mathrm{H}_{4}(1 / 99)$ (a, b) and $\mathrm{C}_{2} \mathrm{H}_{2} / \mathrm{CO}_{2}(50 / 50)$ (c, d) mixtures on $\mathrm{Zn}_{2}$ (bpy) (btec).

Figure 5. (a, b) Single-component adsorption isotherms of $\mathrm{CH}_{4}, \mathrm{C}_{2} \mathrm{H}_{2}, \mathrm{C}_{2} \mathrm{H}_{4}, \mathrm{C}_{2} \mathrm{H}_{6}$, $\mathrm{C}_{3} \mathrm{H}_{4}, \quad \mathrm{C}_{3} \mathrm{H}_{6}, \quad \mathrm{C}_{3} \mathrm{H}_{8}, \quad \mathrm{CO}_{2}, \quad \mathrm{H}_{2}, \quad \mathrm{O}_{2}, \quad$ and $\mathrm{N}_{2}$ in $\mathrm{Zn}_{2}$ (bpy)(btec) at $298 \mathrm{~K} . \quad$ (c, d) Multicomponent breakthrough $(298 \mathrm{~K}, 1$ bar $)$ and desorption $(333 \mathrm{~K}, 1$ bar $)$ curves for $\mathrm{CH}_{4} / \mathrm{C}_{2} \mathrm{H}_{2} / \mathrm{C}_{2} \mathrm{H}_{4} / \mathrm{C}_{2} \mathrm{H}_{6} / \mathrm{C}_{3} \mathrm{H}_{6} / \mathrm{C}_{3} \mathrm{H}_{8} / \mathrm{CO}_{2} / \mathrm{H}_{2}(30 / 1 / 10 / 25 / 10 / 10 / 1 / 13)$ mixtures on $\mathrm{Zn}_{2}$ (bpy)(btec).

Figure 6. Calculated $\mathrm{C}_{2} \mathrm{H}_{2}$ molecule binding sites in $\mathrm{Zn}_{2}$ (bpy)(btec) by GCMC simulation. Color code: $\mathrm{Zn}$ (green), $\mathrm{O}$ (red), $\mathrm{N}$ (light blue), $\mathrm{C}$ (gray), and $\mathrm{C}_{2} \mathrm{H}_{2}$ (blue).

Figure 7. (a) Scale-up synthesis of $\left[\mathrm{Zn}_{2}\right.$ (bpy) (btec) $\left.\left(\mathrm{H}_{2} \mathrm{O}\right)_{2}\right] \cdot 2 \mathrm{H}_{2} \mathrm{O}$. (b) TG and DSC curves for as-synthesized $\left[\mathrm{Zn}_{2}\right.$ (bpy) (btec) $\left.\left(\mathrm{H}_{2} \mathrm{O}\right)_{2}\right] \cdot 2 \mathrm{H}_{2} \mathrm{O}$. (c, d) PXRD patterns of $\left[\mathrm{Zn}_{2}\right.$ (bpy) (btec) $\left.\left(\mathrm{H}_{2} \mathrm{O}\right)_{2}\right] \cdot 2 \mathrm{H}_{2} \mathrm{O}$ after different treatment. (e) Comparison of the heat and water stability of some benchmark MOF materials.

\section{Figure 1}

a

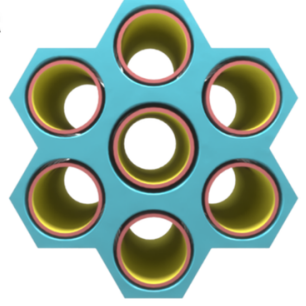

One-dimensional channel b

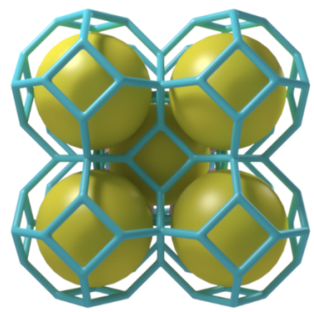

Cage type pore

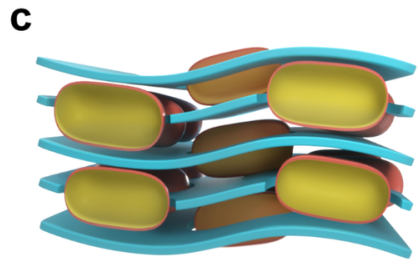

Interlayer cavity

Figure 2

(a)

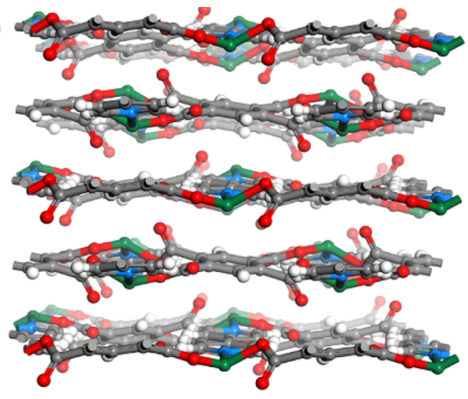

(c)

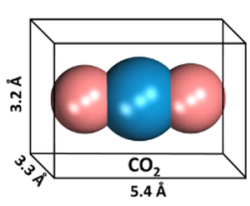

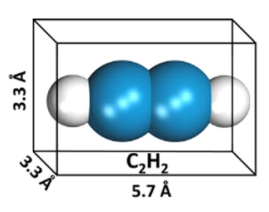
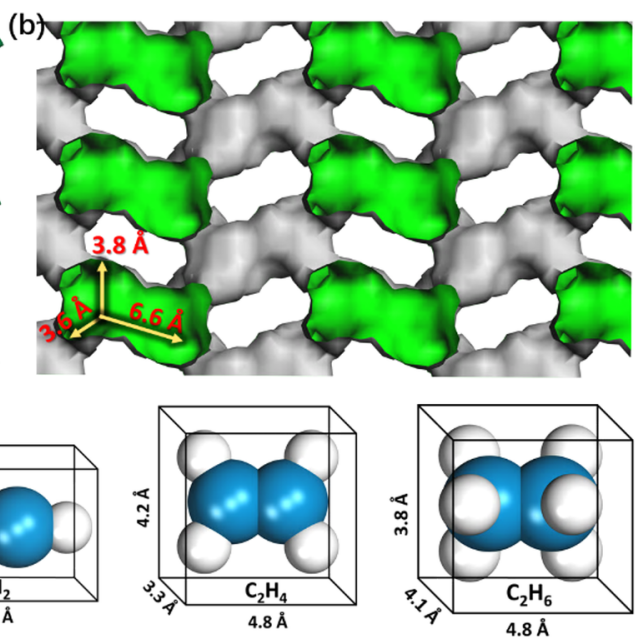
Figure 3
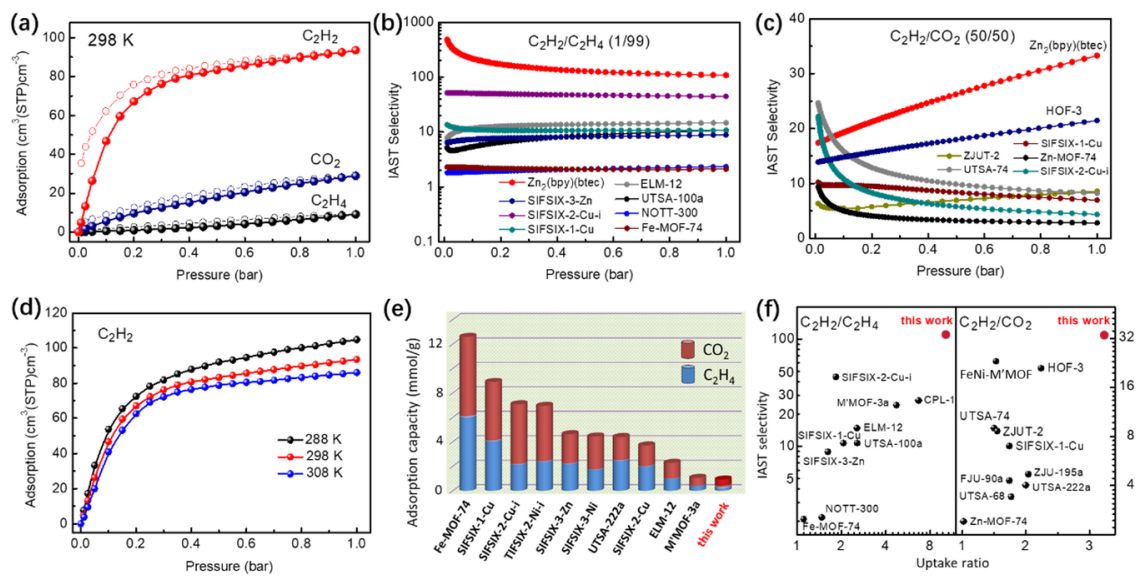

Figure 4
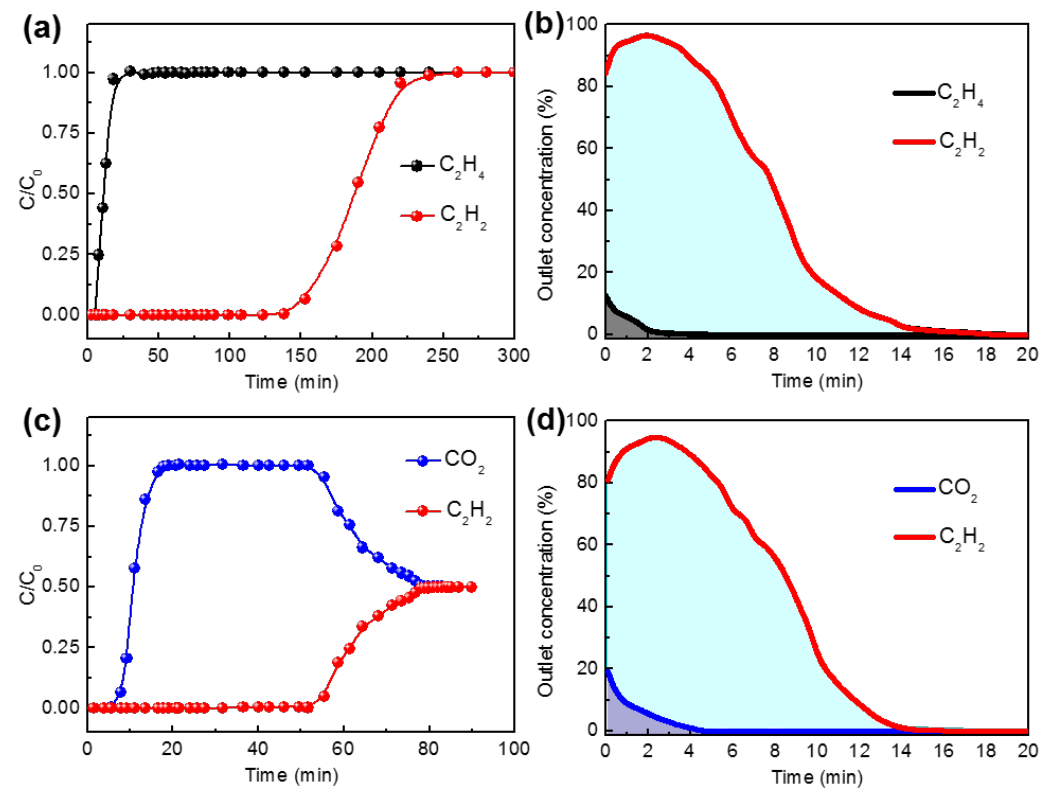

Figure 5 

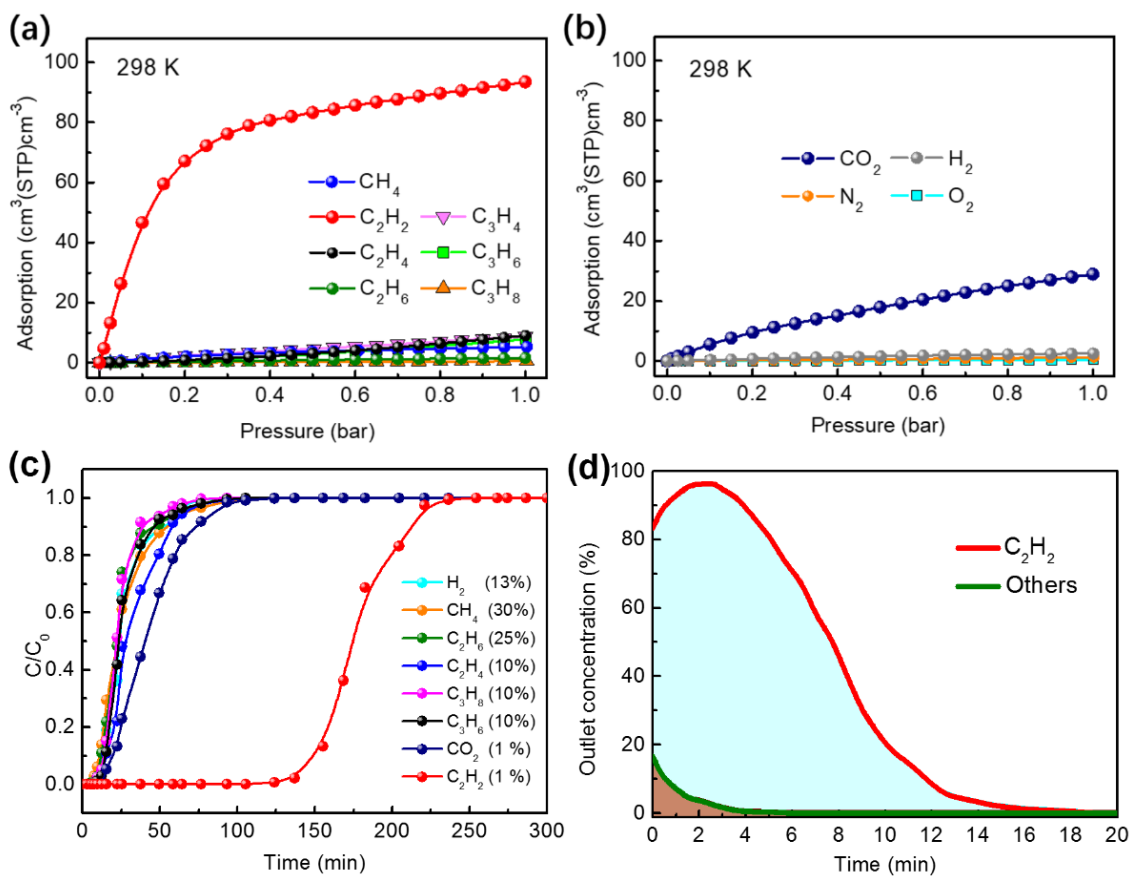

Figure 6

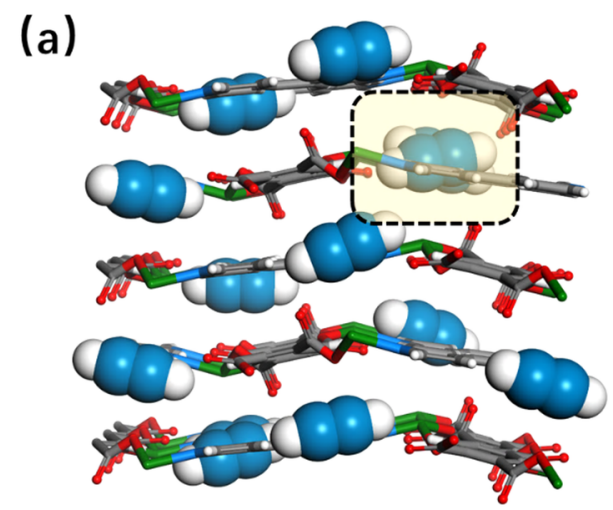

(b)

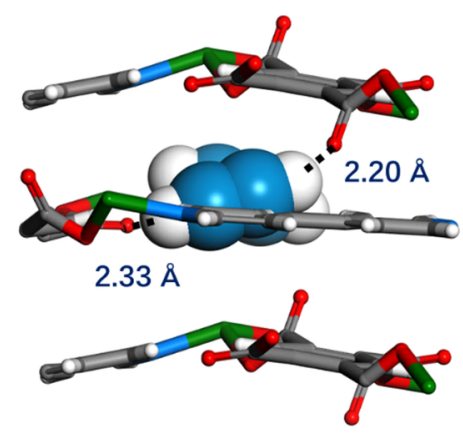

Figure 7 
(a)

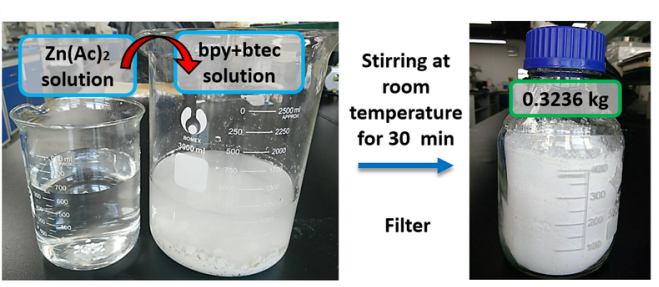

(c)

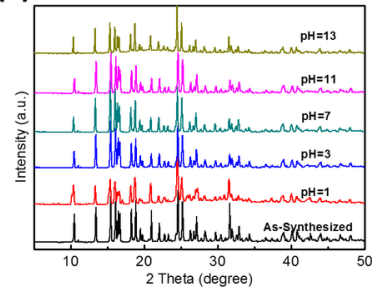

(d)

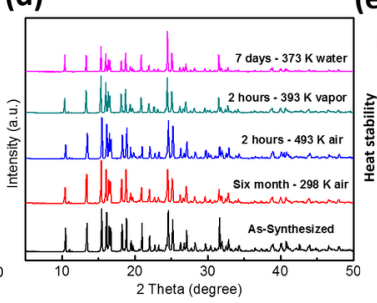

(b)

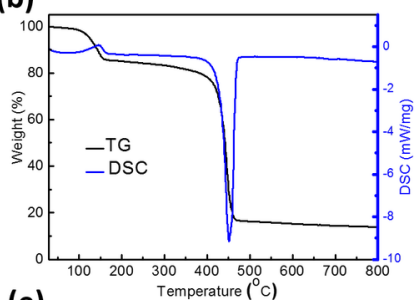

(e)

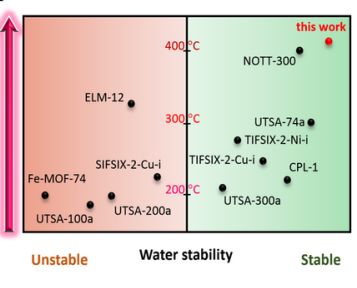

TOC Art

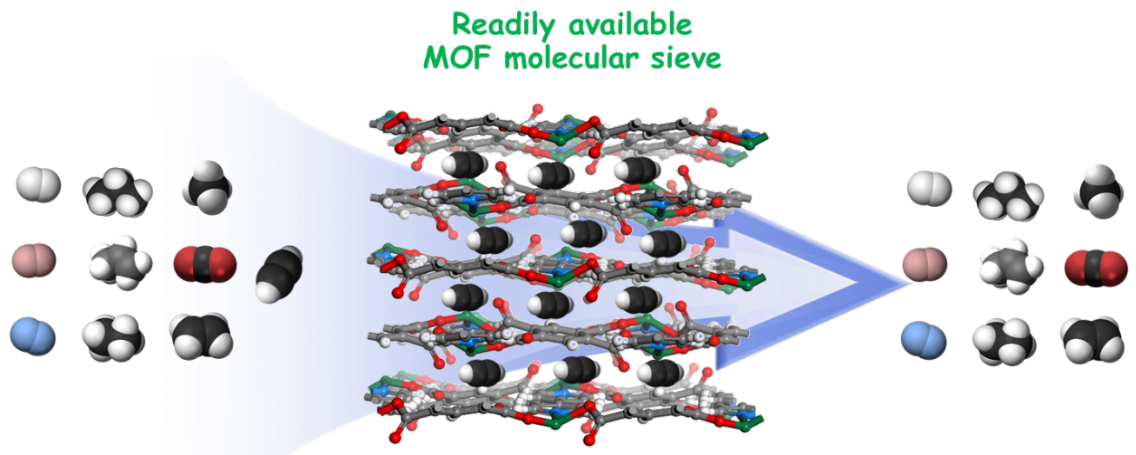

Highly stable structure (acid, base, boiling water) 